\title{
Hydrological Variability from Gauging Stations and Simulated SWOT Data, for Major French Rivers
}

\author{
L. Chevalier1,2, B. Laignel2, I. Turki², F. Lyard'1, C. Lion' \\ ${ }^{1}$ CNES/LEGOS, University of Toulouse, Toulouse, France \\ ${ }^{2}$ University of Rouen, Rouen, France \\ Email: laetitia.chevalier76@gmail.com, benoit.laignel@univ-rouen.fr, imen.turki.cnrs@gmail.com, \\ florent.lyard@legos.obs-mip.fr, christine.lion@legos.obs-mip.fr
}

How to cite this paper: Chevalier, L., Laignel, B., Turki, I., Lyard, F. and Lion, C. (2017) Hydrological Variability from Gauging Stations and Simulated SWOT Data, for Major French Rivers. Journal of Geoscience and Environment Protection, 5, 54-69. https://doi.org/10.4236/gep.2017.513004

Received: September 22, 2017

Accepted: December 26, 2017

Published: December 29, 2017

Copyright (C) 2017 by authors and Scientific Research Publishing Inc. This work is licensed under the Creative Commons Attribution International License (CC BY 4.0).

http://creativecommons.org/licenses/by/4.0/

\begin{abstract}
This study was carried out under the aegis of the program Surface Water and Ocean Topography (SWOT) associated with the National Center of Space Studies (CNES). The future SWOT mission will offer new opportunities to survey the hydrodynamic in the rivers because it will provide data on the water level/ discharges with a high spatial resolution (oceans: $1 \mathrm{~km}$, rivers: $100 \mathrm{~m}$ of width) and with a global cover. However, it is important to estimate the capacity of SWOT to reproduce the hydrodynamic phenomena in the estuaries and the temporal and the spatial variability of this dynamic. The aim of this paper is 1) to estimate the capacity of SWOT to reproduce the hydrological variability of watersheds, and 2) to validate the use of these data for other zone without hydrometric station. Based on discharge measurements and simulated Surface Water and Ocean Topography (SWOT) data, we have investigated the hydrological variability of the main French rivers (Seine, Loire, Garonne and Rhône) by applying a series of statistical analyses to the time series of the discharge. A frequency analysis has been also used using a technique of wavelet. Results have shown a similar hydrological variability of the four watersheds. Three different periods of hydrologic variability has been identified: before 1970, between 1970 and 1990, and after 1990. Using these analyses, simulated SWOT samples and discharges were compared during the three studied periods. Simulated SWOT data, obtained by a synthetic sampling of river discharges basing on the number of measurements per repeat orbit, reproduce the hydrological variability of rivers. Such reproduction seems to be independent in the number of SWOT passages (from two to four), except for the minimum and maximum annual discharges where number of overpass seems to have an influence. These results were validated by coherence wavelet which underlines coherence higher than $90 \%$
\end{abstract}


between simulated SWOT data and in-situ discharges. Nevertheless, good correlation was not observed for the minimum and the maximum annual discharge with an underestimation for SWOT maximum annual and an overestimation of the minimum annual SWOT ones. Moreover, best identification of minimum, mean and maximum annual discharge depends on SWOT overpasses.

\section{Keywords}

Hydrological Variability, Discharge, SWOT, Watershed, Wavelet Analyses

\section{Introduction}

In the present context of intensification of global water cycle associated with climate warming [1] [2], hydrological systems and water resources are continuously affected. Assessing the potential impact of global climate change on hydrological variability becomes crucial, particularly in France, in order to comply with the most recent EU Water Framework Directive and to reduce the potential threats on the national water bodies. The large watersheds, which are integrators of climate change and heterogeneities of many parameters, represent good indicators for global change determination.

Many studies at large global watersheds [3] [4] and at French watersheds [5] [6] have already been performed to characterize the hydrological variability of different global rivers. These studies are usually based on in-situ discharge data. However it is also possible to perform it using satellite data [7] [8]. Recently, a new space mission called Surface Water and Ocean Topography (SWOT) is being developed jointly by a collaborative effort of the international oceanographic and hydrological communities for making high-resolution measurement of the water elevation of both the ocean and land surface water to answer the questions about the oceanic submesoscale processes and the storage and discharge of land surface water. The key instrument payload is a Ka-band radar interferometer capable of making high-resolution wide swath altimetry measurement. Data, collected by Surface Water and Ocean Topography SWOT, will provide measure 2D water heights over a $120 \mathrm{~km}$ wide swath. This satellite allows obtaining water level for all lakes greater than $250 \mathrm{~m}^{2}$ and discharges for river of width of greater than $100 \mathrm{~m}$ [9]. Many studies about the error budget [10] [11] contribution in modeling are carried out to prepare the mission spatial [12] [13].

This study was carried out in the framework of the program Surface Water and Ocean Topography (SWOT) which is a partnership between National Center of Space Studies (CNES) and National Aeronautics and Space Administration (NASA).

The present research focuses on two objectives. The first one is to investigate the hydrological variability in four watersheds of the French rivers using different statistical approaches and frequency analysis with the aim to define a long-term sim- 
ilar variability between the four watersheds (1959-2010). The discharge variability is then compared to SWOT data simulation in order to define the capacity of the satellite to reproduce temporal hydrological variability. The study is divided into five parts. Following the introduction, SWOT mission is detailed in Section 2. Then, Section 3 describes data and methods used to investigate the hydrological variability. The Section 4 introduces the results and discussion. Finally, Section 5 presents conclusions.

\section{Surface Water and Ocean Topography Mission}

The SWOT mission will provide high-resolution measurements of water surface elevations over the ocean and continental surface water bodies. The main satellite payload is the Ka-band Radar Interferometer (KaRIN), a wide swath radar interferometer. Two antennas separated by a $10 \mathrm{~m}$ boom will observe two ground swaths of $50 \mathrm{~km}$ on each side of the nadir separated by $20 \mathrm{~km}$. The distance between the two swaths will be partially covered by the measurements from a nadir altimeter [13] [14]. The intrinsic pixel resolution will vary from $60 \mathrm{~m}$ (near range) to $10 \mathrm{~m}$ (far range) across-track and will be at best around $2 \mathrm{~m}$ along-track (however, this value is also dependent upon decorrelation time). The chosen orbit has a 890.5 $\mathrm{km}$ altitude and $77.6^{\circ}$ inclination, in order to observe almost all the continental surfaces. SWOT will measure water surface elevation for all lakes greater than $250 \mathrm{~m}^{2}$ and rivers with widths greater than $50-100 \mathrm{~m}$, with a vertical precision of at least $10 \mathrm{~cm}$ [14]. The satellite is currently planned to be launched in 2020. The nominal lifetime of the mission ranges approximately between 3 and 5 years. The first three months will be a calibration-validation period. After the initial three months, the remaining time during the mission will be undertaken with an orbit that meets the nominal science requirement to obtain a global coverage of the earth and that has a 21 days repeat. Number of observations change according to the localization of study domain per repeat period (21 days) for this orbit (890.5 $\mathrm{km})$.

\section{Data set and Methods}

The different hydrometric stations Montjean sur Loire, Poses, Beaucaire and Mas d'Agenais have been selected, as explored previously in [15], to investigate the hydrological variability of Loire, Seine, Rhone and Garonne rivers, at long term scales (Figure 1). Daily river discharge time series of Seine, Rhone and Loire rivers were extracted from the database of Banque Hydro

[http://www.hydro.eaufrance.fr/selection.php (accessed 17 July 2013)]. Garonne data have been provided by Bordeaux harbor "Grand Port Maritime de Bordeaux". Hydrometric stations have been selected according to two criteria: 1) the longest time series which requires measurements between 1959 and 2010; and 2) the shortest distance between the studied station and the outlet, for river area not subject to tidal influence.

The discharge data have been used to extract synthetically SWOT samples 


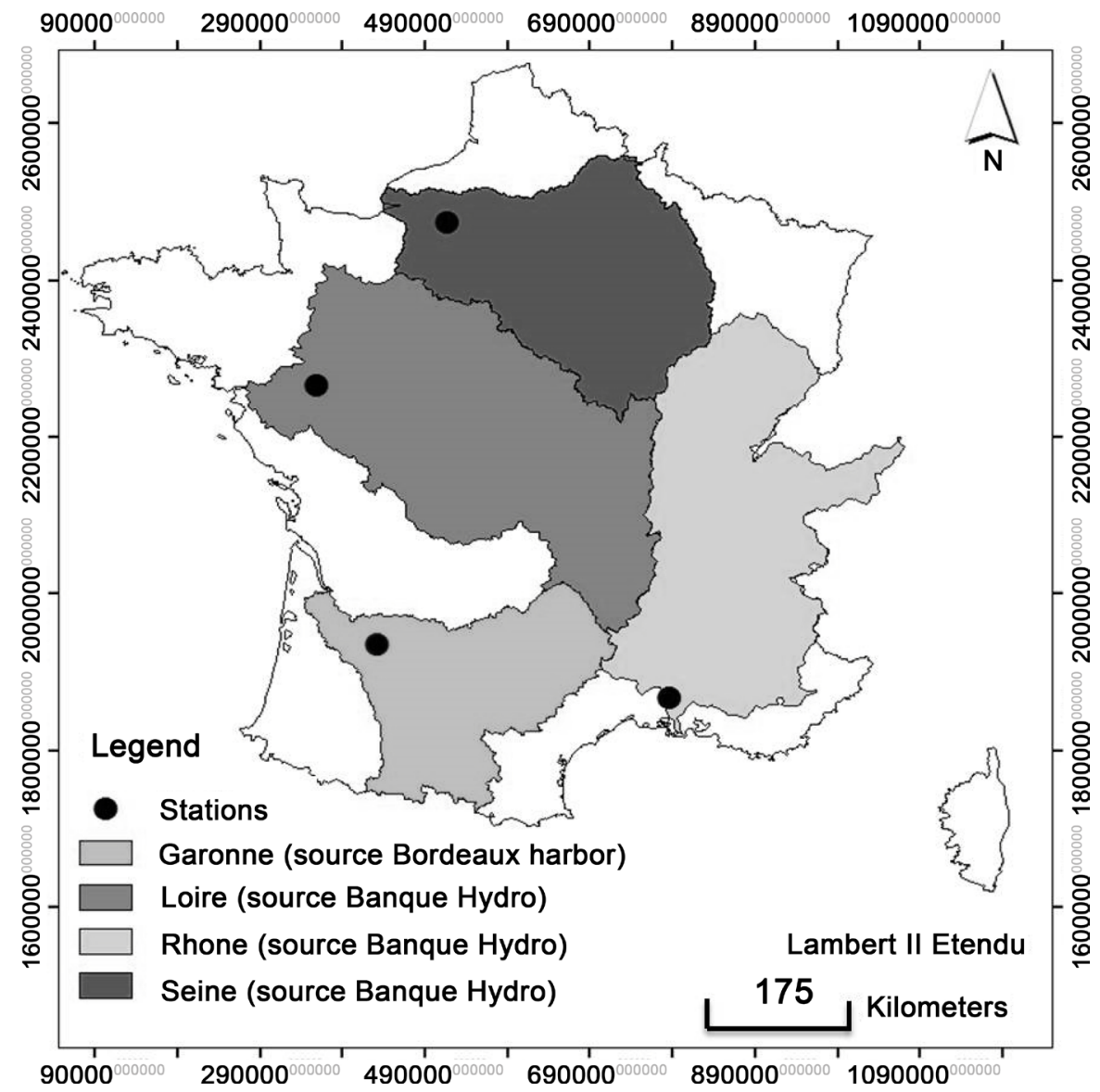

Figure 1. The main French rivers and their hydrometric stations used for this study.

Table 1. SWOT overpass at each location: Seine, Garonne, Loire and Rhone.

\begin{tabular}{cccccccc}
\hline Rivers & Latitude & Longitude & Numbers of SWOT passages & Temporal sampling intervals \\
\hline Seine & 49.31 & 1.24 & 3 & 4.19 & 11.57 & 15.12 \\
Garonne & 44.24 & 0.13 & 2 & 4.19 & 12.57 & \\
Loire & 47.23 & 0.51 & 4 & 1.63 & 4.19 & 15.12 & 20.5 \\
Rhone & 13.48 & 4.39 & 3 & 0.63 & 2.18 & 20.50 \\
\hline
\end{tabular}

according to the number of overpasses per repeat cycle (21 days) and the selected orbit $(890.5 \mathrm{~km})$. The number of SWOT samples and the temporal sampling intervals were calculated for each hydrometric station of its geographical coordinates (Table 1).

First, qualitative statistics (minimum, mean and maximum yearly values) have been applied to the discharge time series to quantify the variability of French rivers discharges.

Then, trend analysis in discharge was realized using a local polynomial regression non-parametric algorithm (LOESS), proposed by [16] and developed by [17]. The locally weighted polynomial non-parametric fitting procedure is applied using three degrees of smoothing successively in decreasing order so as to emphasize both trend behavior and get a first approach of the main leading fluctuations in the se- 
ries. The three smoothing windows used span, respectively, 100\%, 25\% and 10\% of the data.

Finally, continuous wavelet (CWT) was used to decompose a signal on the basis of scaled and translated versions (daughter wavelets) of a reference wave function (mother wavelet). Here, CWT has been used in univariate mode aiming to identify more accurately the dominant modes of variability as spectral components and the time scales involved. For a more complete overview of CWT analysis and its application to hydrometeorological or climatic signals, the reader is referred to literature [15] [18] [19] [20].

\section{Results and Discussion}

\subsection{Characterization of the Hydrological Variability of the French River from the in Situ Measurements}

Using the methods presented previously, the discharge in the different French rives have been studied. Figure 2 presents the variations about the mean of each annual series of maximum, minimum and mean discharges. The values are not standardized, in order to preserve information on discharge. A LOESS smoothing, also shown in the same figure, has been applied to time series (maximum, minimum and mean yearly discharges). The comparisons between the discharges evolutions in time define five identical periods for all rivers: before 1970, between 1970 and 1980, between 1980 and 1990, between 1990 and 2000 and after 2000.

For Seine River, as demonstrated by [6], a change from below-to above average values can be observed for the maximum, mean and minimum annual series, located around the mid-1970s. Before 1970, the maximum annual discharges decrease where the mean and the minimum annual discharges show a slight increasing followed by a decreasing trend. Then, the general trend can described by an increasing between 1970 and 1980, a decreasing between 1980 and 1990, an increasing between 1990 and 2000 and decreasing after 2000. Similarly, Loire discharges illustrate a series of successive discontinuities (mid 1970s, 1980, 1990 and 2000), excepted before 1970 when the mean annual discharges increase. In the case of Garonne, before 1970, the maximum annual discharges decrease, the mean and the minimum annual discharges increase. Between 1970 and 1980, the maximum, the mean and the minimum annual discharges increase. Between 1980 and 1990, the maximum, the mean and the minimum annual discharges decrease. Between 1990 and 2000, the maximum and the mean annual discharges increase, then decrease. After 2000, the maximum annual discharge increase and the mean annual discharges decrease. The minimum annual discharges keep a constant trend after 1990. Regarding Rhone River, a decreasing trend was observed before 1970 which increases in 1970-1980 and decreases in 1980-1990. Between 1990 and 2000, the maximum, the mean and the minimum annual discharges increase and then decrease after 2000.

According to these results, five periods with different hydrological variability 

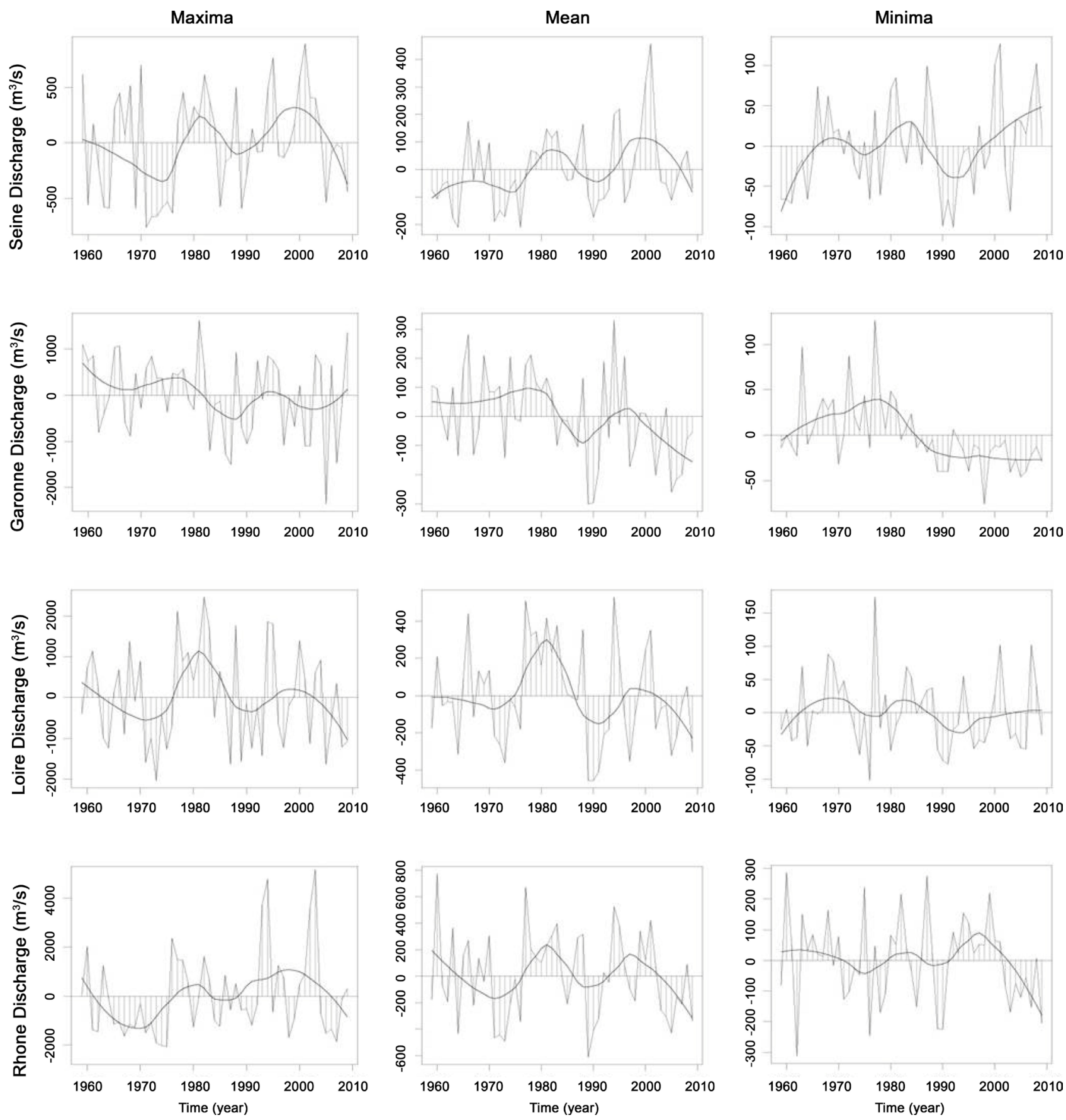

Figure 2. Annual discharge time series for French watersheds (from left to right: annual maximum, mean and minimum discharge). LOESS smoothing (locally weighted polynomial fitting) is performed for each time series.

can be defined showing four main discontinuities: 1970, 1980, 1990 and 2000.

Following, LOESS smoothing was applied to daily time series of discharges. Different degrees of smoothing (100\%, 25\% and 10\%) have been tested. Only, a 25\%-span smoothing is presented in Figure 3 since similar results have been obtained with other smoothing degrees. This evolution highlights the presence of well-structured interannual fluctuations with increasing amplitudes at the end of the period of study. 

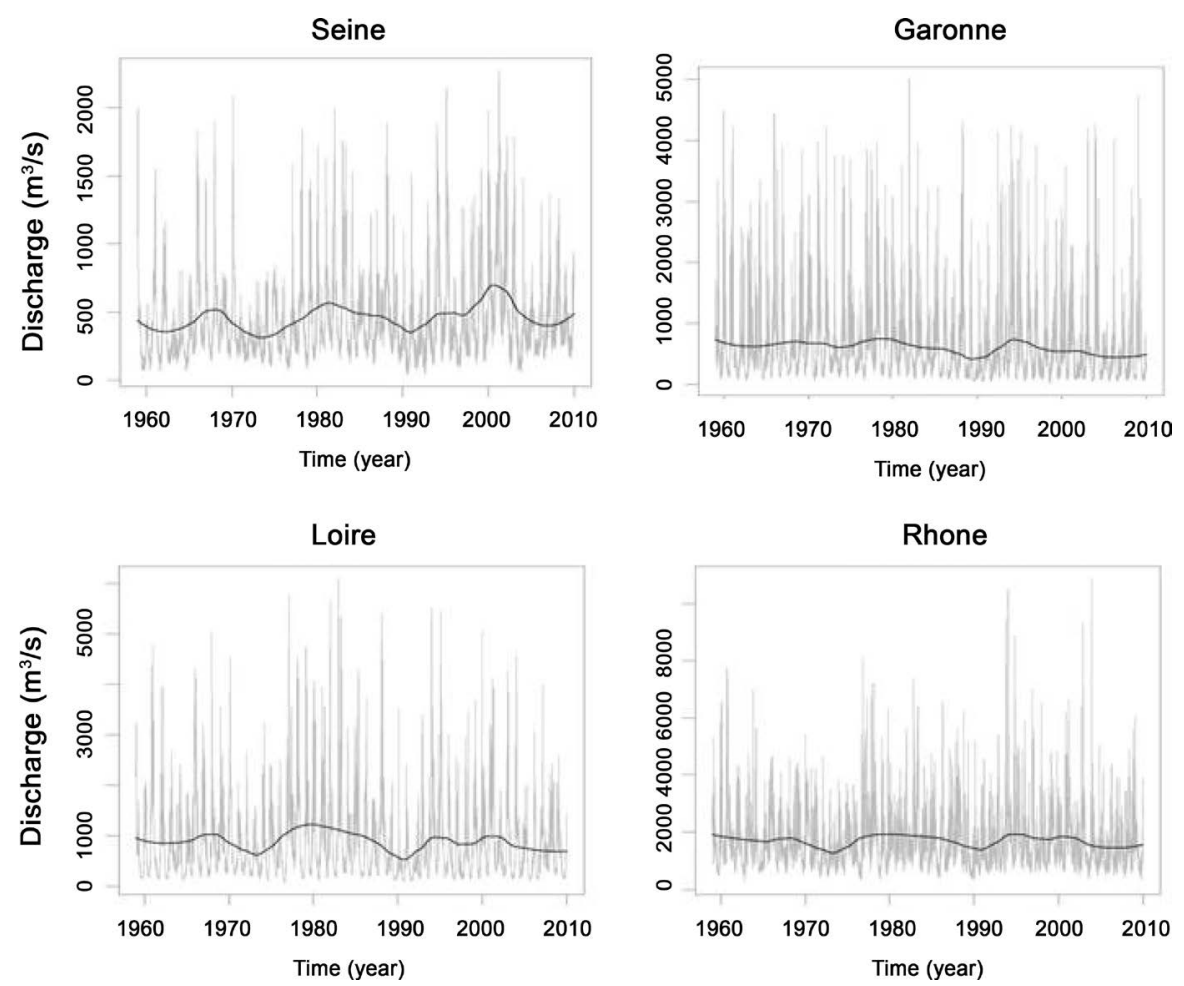

Figure 3. Daily discharge in grey and 25\%-span LOESS in black lines for 1959-2010.

Then, the time variability of discharges has been deeply investigated using a frequency analysis of wavelet which is displayed in Figure 4. Here, the CWT show four modes of variability, statistically tested by Monte Carlo simulation against white noise (AR $(1)=0$ ) with confidence level of $90 \%$, as the following: 1) 1 year band (annual hydrological cycle), 2) 2 - 4 year band in 1960s and 1970s detected only for Garonne and Rhone (this band present lower energy than other band), 3) 5 - 8 year band from 1980-1990s, except for Rhone where this mode is present during the full period of study, 4) $16-32$ year band during the full time period except for Garonne where this mode appears since 1980. Similarities of the variability modes were detected for all studied basins, except the 2 - 4 year band which is only present at Garonne and Rhone for these time series (19592010). However, 2 - 4 year band is detectable for Seine and Loire despite this band is not significant (it is not represented by the black and white dotted line which indicates the modes of variability statistically tested at a confidence level of $90 \%$ ). For the Seine discharges, this point is validated by [21] indicating $2-4$ year band between 1940 and 1970, for other time series (1940-2010). For all similarities between watersheds, many discontinuities are observed: 1) 1960, 1970 at Seine and Rhone, and 1990 at Loire, Garonne and Rhone for the 1 year mode, 2) 1980s associated to the appearance at Loire, Seine and Garonne of the 5 - 8 year band which is observed since 1960 at Rhone; while the 2 - 4 year mode disappears at Rhone and Garonne. Some similarities in the frequency mode were emphasized, despite these small differences observed in French watersheds discharges. 
(a) Seine

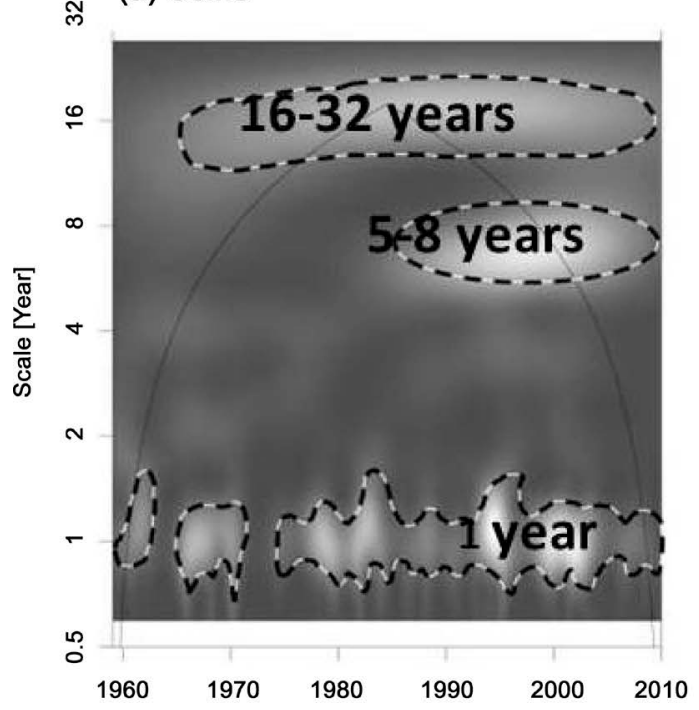

(c) Loire

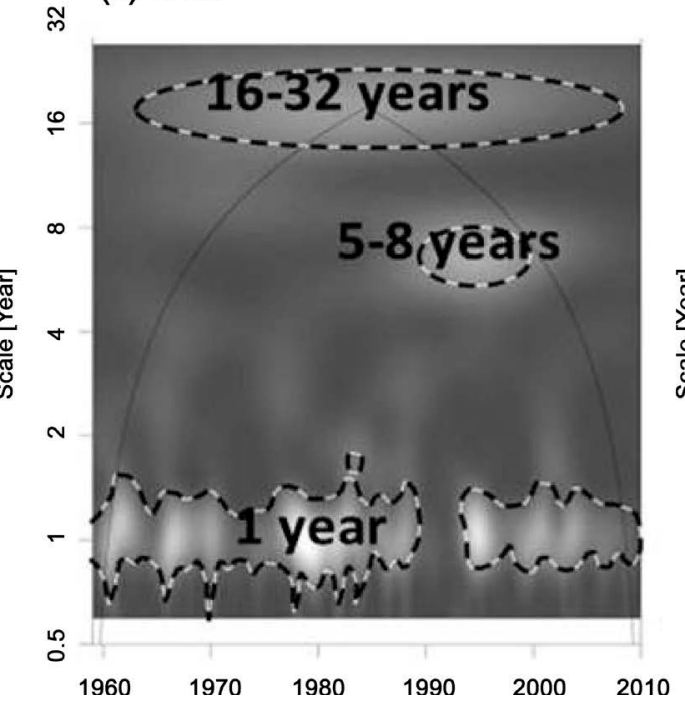

(b) Garonne

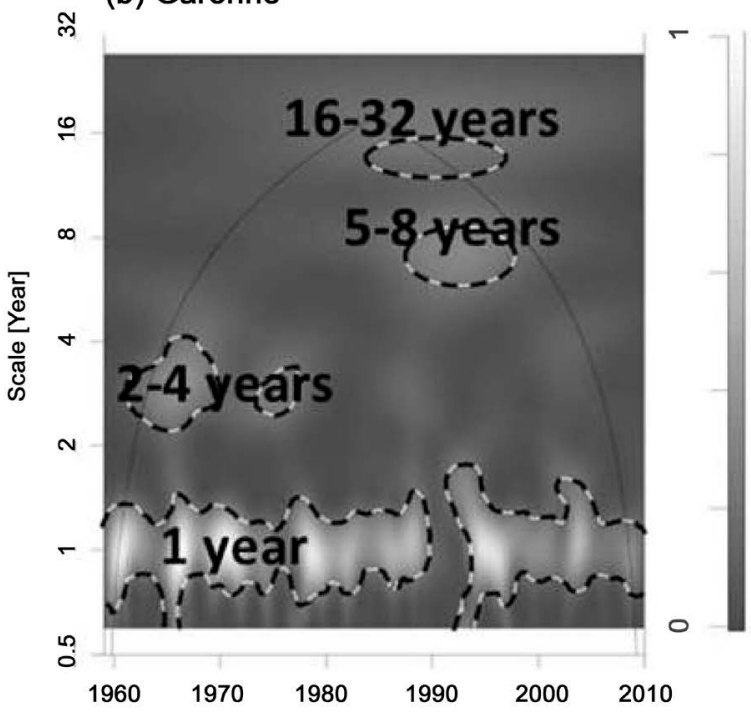

(d) Rhone

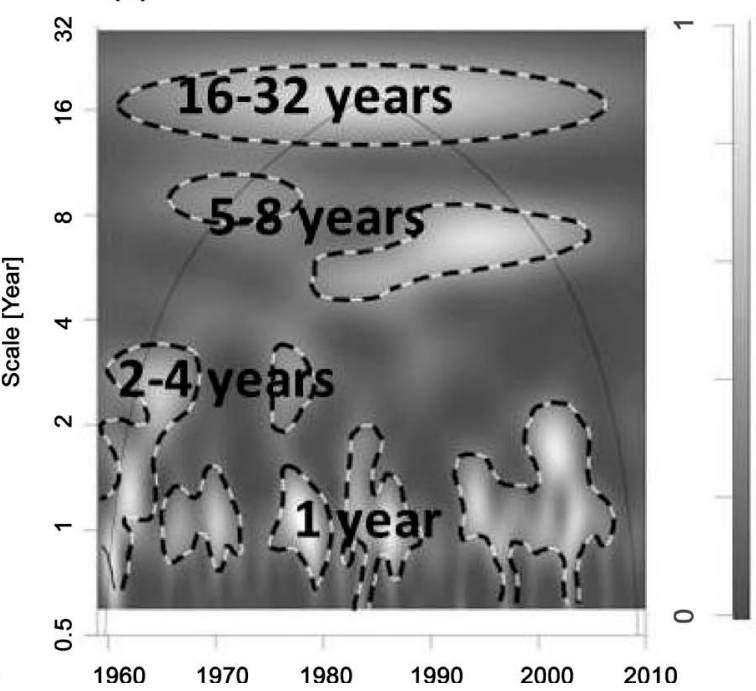

Figure 4. Wavelet analyzes of discharges of the Seine (a), the Garonne (b), the Loire (c) and the Rhone (d) (the black and white dotted line indicate the modes of variability statistically tested at a confidence level of $90 \%$; the black line indicates the cone of influence; the white colour indicates the presence of mode of variability).

Obtained results, using different approaches, show a similar hydrological variability between the four studied French watersheds. Then, three periods are indicated: 1) before 1970, 2) between 1970 and 1990, and 3) after 1990. These findings are also confirmed by previous works. Indeed, two discontinuities in hydrological time series has been detected by [22] which have concluded the occurrence of a step increase in discharge variability around 1970. [23] and [24] have studied 79 rivers by wavelet analyses and have shown striking climate-related features before the 1950s and after the 1970s in mean annual discharges. [21] have demonstrated discontinuities, in 1970s and 1990s, around 1970 and 1990 on both in the precipitation, discharge and piezometry of the Atlantic Ocean watersheds (NW France, N Africa, USA). 
According to these analyses, three periods with different hydrological variability can be observed: 1) after 1970, 2) between 1970 and 1990 and 3) after 1990.

\subsection{Determination of the Hydrological Variability Observed by SWOT}

SWOT samples have been simulated during a series of time periods of 5 years. Three periods were selected (1965-1969, 1985-1989 and 2000-2004) and the methods, used previously, were applied to sampled data in order to visualize influence of numbers of SWOT passages on hydrological variability restitution by SWOT.

Initially, compared results of maximum, mean and minimum annual values were studied for 1965-1969, 1985-1989 and 2000-2004 period. Figure 5 represents the maximum, mean and minimum annual values for in-situ (black) and simulated SWOT (grey) data of the four watersheds and for three periods.

Generally, variations of mean annual SWOT data are similar to those of discharges. The annual maximum, mean and minimum discharge is tendency to decrease, except for annual minimum of Garonne and Loire for 1965-1969 periods. However, whatever tendency the ability of SWOT to it reproduces is well. However, the maximum and the minimum annual data were underestimated and overestimated, respectively (Figure 5). In order to quantify underestimation and overestimation, averages of under/overestimation are calculated for each river and for three periods (Table 2 and Table 3). For minimum annual data (Table 2), overestimation is more important to Rhone, where average of overestimation by SWOT is greater than $200 \mathrm{~m}^{3} \cdot \mathrm{s}^{-1}$. Average of overestimation by SWOT for Seine, Loire and Garonne River is less than $60 \mathrm{~m}^{3} \cdot \mathrm{s}^{-1}$. For maximum annual data (Table 3), underestimation is more important to Rhone, where average of underestimation by SWOT is between $717 \mathrm{~m}^{3} \cdot \mathrm{s}^{-1}$ and $3026 \mathrm{~m}^{3} \cdot \mathrm{s}^{-1}$. Average of underestimation by SWOT for Garonne is between $460 \mathrm{~m}^{3} \cdot \mathrm{s}^{-1}$ and 747 $\mathrm{m}^{3} \cdot \mathrm{s}^{-1}$. For Loire, average of underestimation is between $203 \mathrm{~m}^{3} \cdot \mathrm{s}^{-1}$ and 332 $\mathrm{m}^{3} \cdot \mathrm{s}^{-1}$. Average of underestimation by SWOT for Seine is less than $132 \mathrm{~m}^{3} \cdot \mathrm{s}^{-1}$. To conclude, SWOT seems less good restitute 1) maximum annual data for Rhone and Garonne, and 2) minimum annual data for Rhone. These over and underestimations for the maximum and the minimum annual SWOT data are due to probability that SWOT passages coincide with the maximum and the minimum of discharges.

Underestimation and overestimation for the maximum and the minimum annual SWOT data can be explained by the sampling effect. Figure 6 shows discharge in black and sampling SWOT data in grey circle indicating that the maximum and the minimum discharges are less sampled than other values. This point associated with high peak floods for Rhone and Garonne can explain the worst restitution for maximum annual SWOT data for both rivers. However, peak floods of Loire present also high value and minimum/maximum annual values are better restituted by SWOT. Loire presents four passages of SWOT unlike other rivers. It seems to appear a better restitution of maximum/minimum annual value 


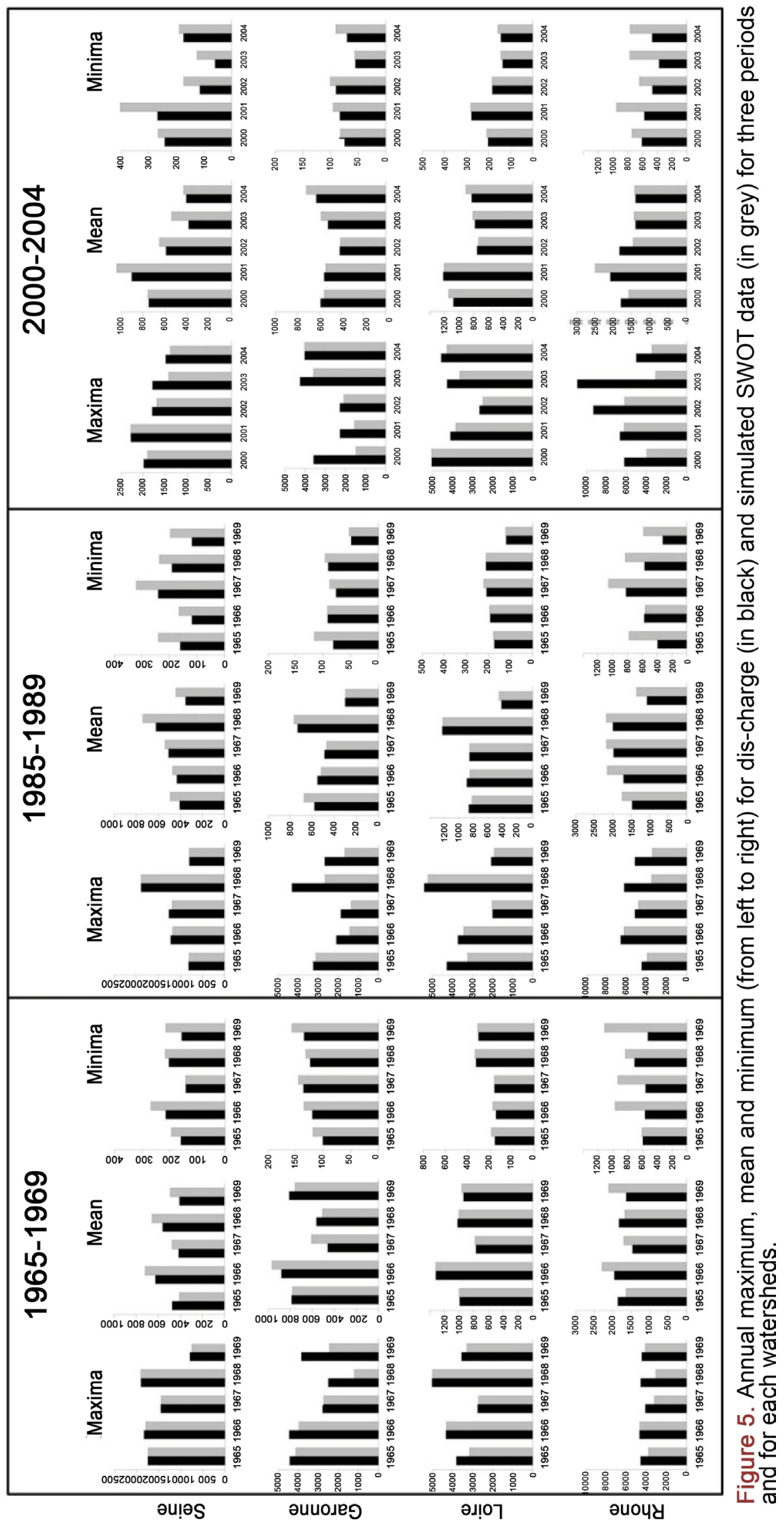


Table 2. Average of overestimation for minimum annual data by SWOT $\left(\mathrm{m}^{3} \cdot \mathrm{s}^{-1}\right)$.

\begin{tabular}{cccc}
\hline & $1965-1969$ & $1985-1989$ & $2000-2004$ \\
\hline Seine & 32 & 65 & 60 \\
Garonne & 14 & 10 & 8 \\
Loire & 8 & 4 & 6 \\
Rhone & 293 & 225 & 276 \\
\hline
\end{tabular}

Table 3. Average of underestimation for maximum annual data by SWOT $\left(\mathrm{m}^{3} \cdot \mathrm{s}^{-1}\right)$.

\begin{tabular}{cccc}
\hline & $1965-1969$ & $1985-1989$ & $2000-2004$ \\
\hline Seine & 21 & 6 & 132 \\
Garonne & 460 & 747 & 743 \\
Loire & 203 & 332 & 274 \\
Rhone & 717 & 1143 & 3026 \\
\hline
\end{tabular}
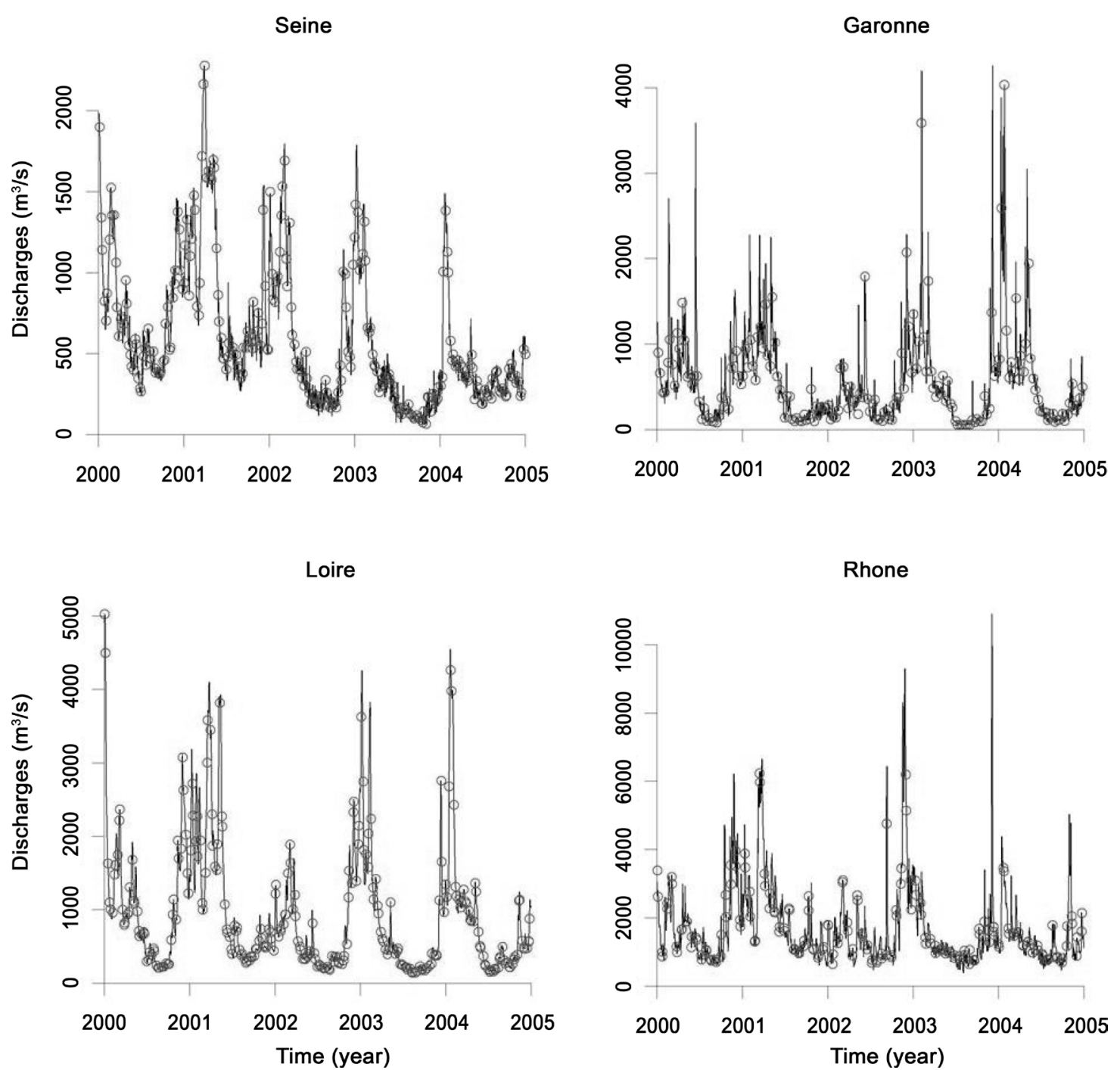

Figure 6. Daily discharge (black line) and simulated SWOT data (grey circle). 
by SWOT for higher number of SWOT passages.

Secondly, different degrees of LOESS (100\%, $25 \%$ and $10 \%$ of data) were studied. The same results were obtained for different rivers. The results for only on Rhone River are presented in Figure 7 which shows a strong similarity of loess provided by in-situ discharges and simulated SWOT data. The same variation between both span-LOESS was also observed.

SWOT can reproduce general trends of discharges. However, simulated SWOT data could not describe the maximum annual values and the peak flood events which are poorly shown.

In frequency domain, wavelet analyses were performed (Figure 8) for discharge and simulated SWOT data of Rhone between 2000 and 2004.

Figure 8 shows the same mode of variability for discharges in situ and simulated SWOT data: 1) two year mode, 2) one year mode, 3) six months mode (corresponding at 0.5 years of the Figure 8 ) in 2001 and 2003, and 4) two-three months mode (corresponding at 0.125 and 0.25 years of the Figure 8 ) located in December and January of each year. One year mode corresponds to annual hydrological cycle, and six months mode corresponds to half of year mode. Six months mode is probably associated to annual hydrological cycle. The reconstruction in temporally in domain of two-three months mode, using inverse Fourier transform, confirms the presence of this mode in December and January (Figure 9). Indeed, the variability is higher in December and January.

In order to quantify the coherence between both variables, wavelet coherence is realized. Wavelet coherence is useful to determine the similar patterns of variability between simulated SWOT data and discharge. The wavelet analyses

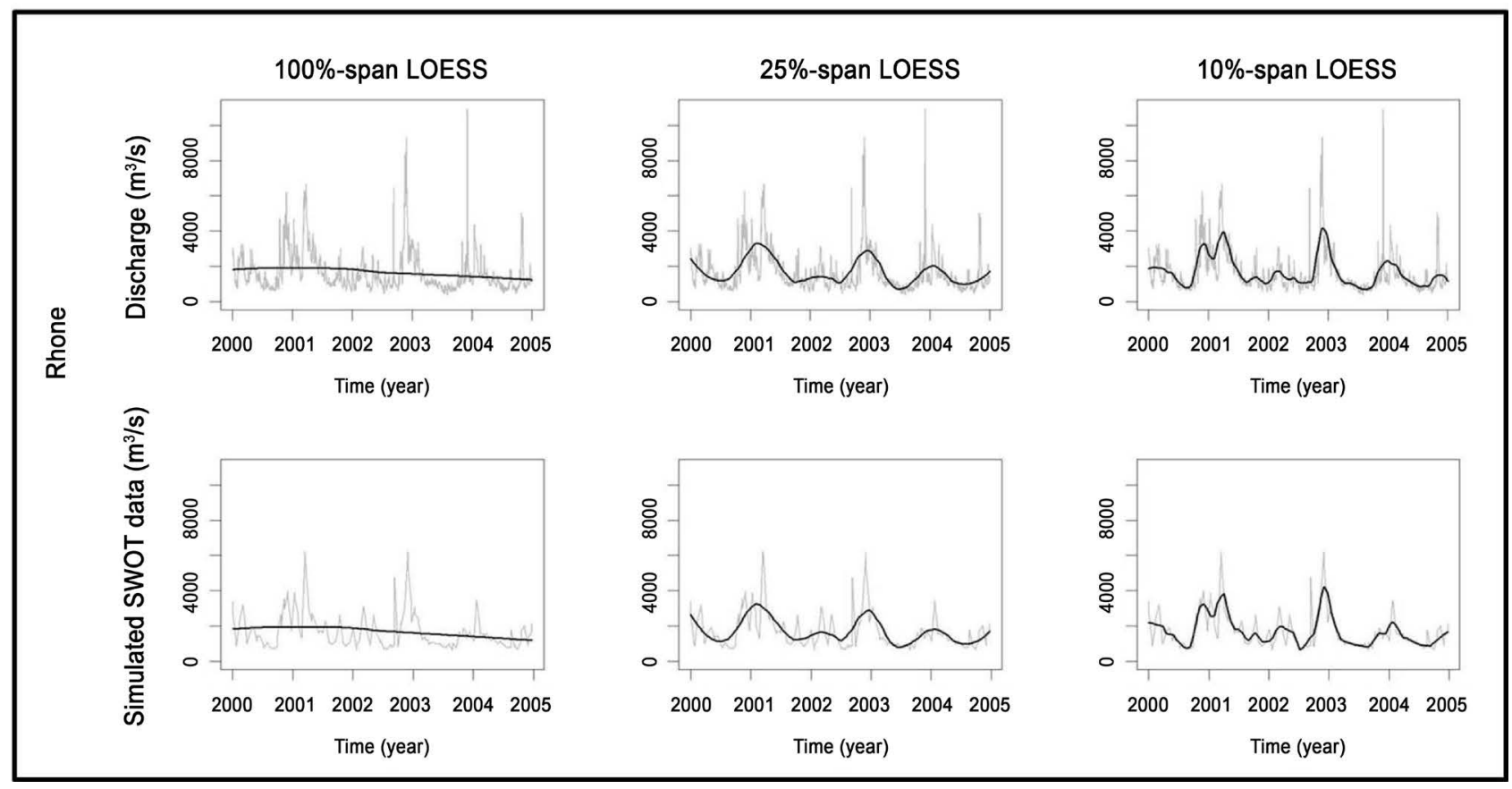

Figure 7. Daily discharge and simulated SWOT data in grey (from top to bottom) and different degrees of LOESS in black lines (from left and right: 100\%, 25\% and 10\% span LOESS) for Rhone for 2000-2004. 


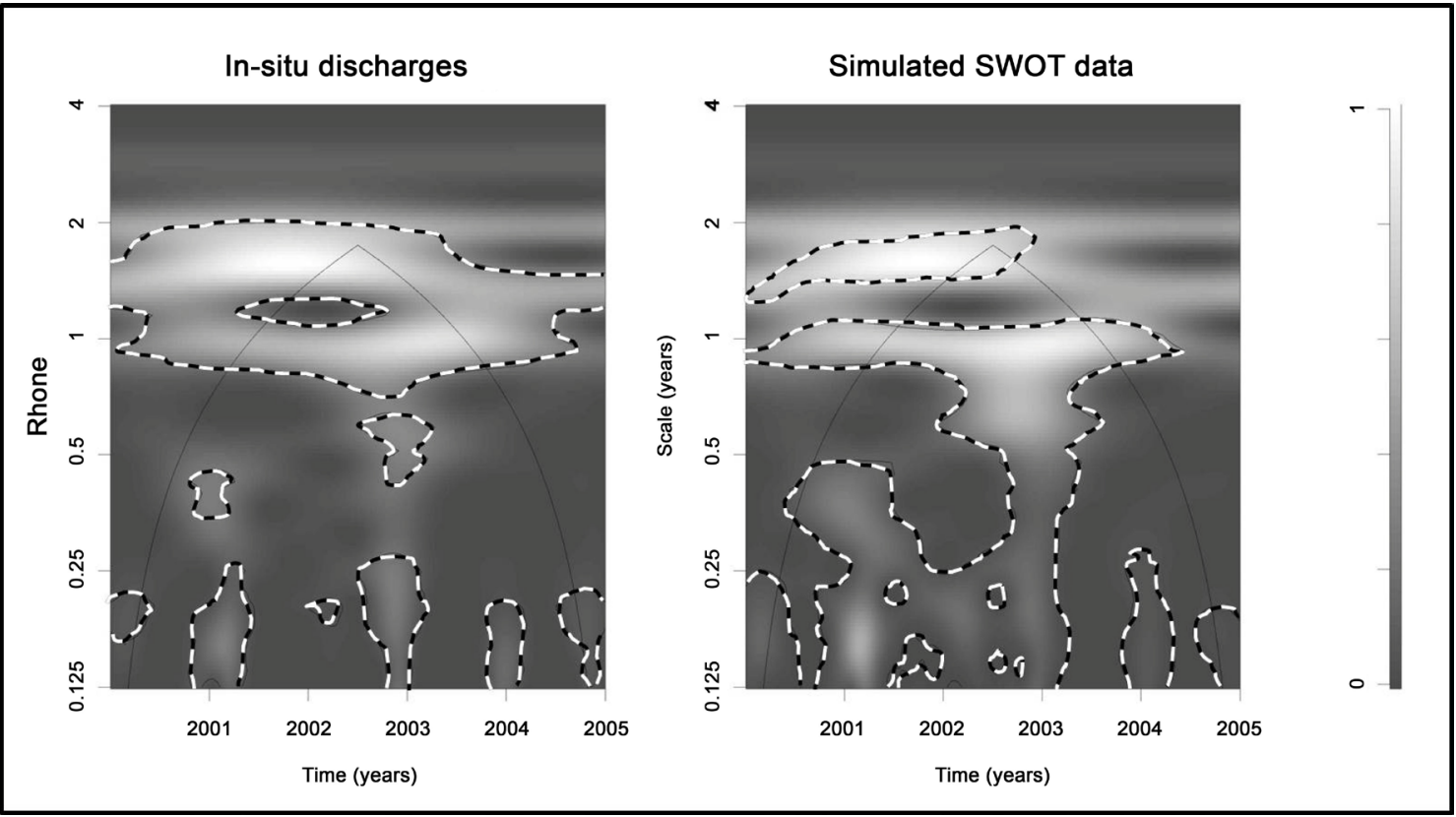

Figure 8. Wavelet analyzes of discharges and simulated SWOT data of Rhone, between 2000 and 2004 (the grey line indicate the modes of variability statistically tested at a confidence level of $90 \%$; the black line indicates the cone of influence; the white colour indicates the presence of mode of variability).

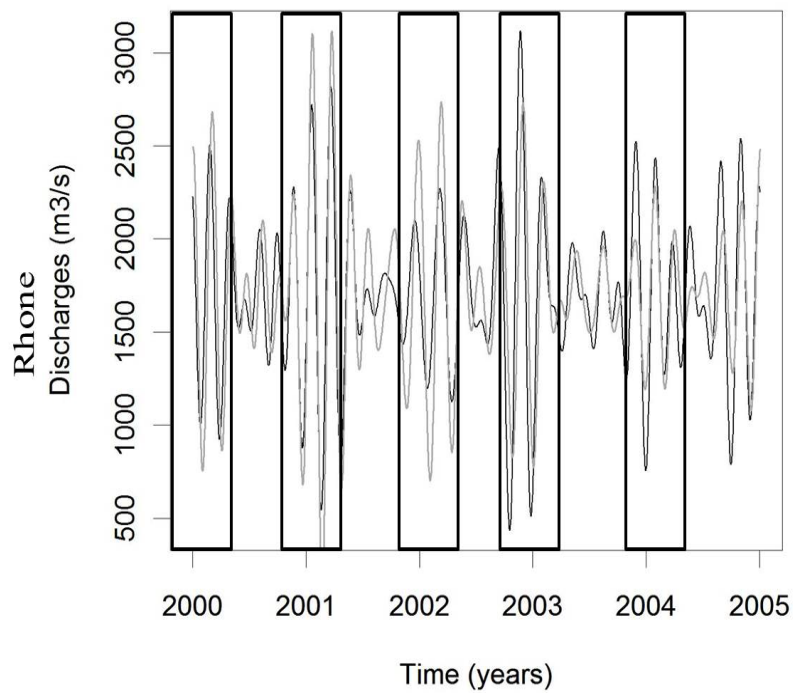

Figure 9. Reconstruction in temporal domain of two-three months mode, for Rhone, discharges (in black) and simulated SWOT data (in grey), between 2000 and 2004.

Table 4. Coherence percentage obtained by wavelet analyses between the variability of discharge of the French watersheds and simulated SWOT observation, for three periods, between 0.125 and 4 years frequencies.

\begin{tabular}{cccc}
\hline & $1965-1969$ & $1985-1989$ & $2000-2004$ \\
\hline Seine & $99.50 \%$ & $99.06 \%$ & $99.38 \%$ \\
Garonne & $96.36 \%$ & $98.44 \%$ & $96.25 \%$ \\
Loire & $98.84 \%$ & $99.02 \%$ & $98.39 \%$ \\
Rhone & $95.75 \%$ & $91.30 \%$ & $94.73 \%$ \\
\hline
\end{tabular}


estimate the wavelet coherence of two time series objects with the Morlet wavelet. Wavelet coherences indicate a strong coherence between the variability of discharge and simulated SWOT data: coherence higher than 90\% (Table 4) for all watersheds.

\section{Conclusions}

This study focuses on the hydrological variability of four French watersheds (Seine, Loire, Garonne and Rhone) with different features basing on discharges (in situ measurements) and simulated SWOT data by the use of a series of statistical analyses.

Time series and spectral analyses of in-situ data between 1959 and 2010 show same results between four watersheds. A high similarity of variability's modes was found for the four stations, with: 1 year, 2 - 4 year, 5 - 8 year and 16 - 32 year modes. The coherence between the four basins was important ranging between $73 \%$ and $92 \%$ for discharge during the period between 1959 and 2010 . Moreover, three periods are identified: 1) before 1970, 2) between 1970 and 1990, and 3) after 1990.

These three periods were chosen for the simulation of SWOT samples which was released during three periods of 5 years: 1968-1969, 1985-1989 and 2000-2004. The comparison between in-situ discharge and simulated SWOT data has demonstrated similar results showing a strong capacity of the satellite to reproduce the hydrological variability of rivers despite the number of SWOT passages. Furthermore, comparison shows that SWOT has difficulties to reproduce the minimum and the maximum annual: the minimum annual discharge is over-estimated and the maximum annual discharge is under-estimated. This discrepancy in estimation seems to be more important for the rivers with high peak flood such as Rhone, Loire and Garonne. However, the river of Loire having four SWOT passages shows a good reproduction of maximum/minimum annual values by SWOT. Best identification of minimum, mean and maximum annual discharge depends on SWOT overpasses. Coherence wavelet indicates a correlation higher than $90 \%$ between both variables. The same modes of variability are detected by wavelet analyses: one year mode corresponding to annual hydrological cycle, six months mode associated to annual hydrological cycle, and two-three months mode corresponding to annual flood period.

This finding shows that satellite data provided by SWOT represents a useful step to characterize the variability of hydrological systems and water resources. This database can be an excellent alternative to study the evolution in rivers where the measurements are not available and for large spatial scales. However, care must be taken when using data for rivers with discharges at high peak floods.

\section{Acknowledgements}

The authors would like to thank CNES, Upper-Normandy region and TOSCA program of SWOT for financial support. 


\section{References}

[1] Bates, B.C., Kundzewicz, Z.W., Wu, S. and Palutikof, J.P. (2008) Climate Change and Water Technical Paper of the Intergovernmental Panel on Climate Change. IPCC Secretariat, Geneva, 210.

[2] Labat, D., Goddéris, Y., Probst, J.L. and Guyot, J.L. (2004) Evidence for Global Runoff Increase Related to Climate Warming. Advances in Water Resources, 27, 631-642. https://doi.org/10.1016/j.advwatres.2004.02.020

[3] Rimbu, N., Boroneant, C., Buta, C. and Dima, M. (2002) Decadal Variability of the Danube River Flow in the Lower Basin and Its Relation with the North Atlantic Oscillation. International Journal of Climatology, 22, 1169-1179. https://doi.org/10.1002/joc.788

[4] Marengo, J.A. (2005) Characteristics and Spatio-Temporal Variability of the Amazon River Basin Water Budget. Climate Dynamics, 24, 11-22. https://doi.org/10.1007/s00382-004-0461-6

[5] Etchevers, P., Golaz, C. and Habets, F. (2001) Simulation of the Water Budget and the River Flows of the Rhone Basin from 1981 to 1994. Journal of Hydrology, 244, 60-85. https://doi.org/10.1016/S0022-1694(01)00332-8

[6] Massei, N., Laignel, B., Deloffre, J., Mesquita, J., Motelay, A., Lafite, R. and Durand, A. (2010) Long-Term Hydrological Changes of the Seine River Flow (France) and Their Relation to the North Atlantic Oscillation over the Period 1950-2008. International Journal of Climatology, 30, 2146-2154. https://doi.org/10.1002/joc.2022

[7] Campos, I.O., Mercier, F., Maheu, C., Cochonneau, G., Kosuth, P., Blitzkow, D. and Cazenave, A. (2001) Temporal Variations of River Basin Waters from Topex/Poseidon Satellite Altimetry. Application to the Amazon Basin. Comptes Rendus de l'Académie des Sciences, 333, 633-643.

[8] Zakharova, E.A., Kouraev, A.V., Cazenave, A. and Seyler, F. (2006) Amazon River Discharge Estimated from TOPEX/Poseidon Altimetry. Comptes Rendus Geosciences, 338, 188-196. https://doi.org/10.1016/j.crte.2005.10.003

[9] Fu, L.L., Alsdorf, D., Rodriguez, E., Morrow, R., Mognard, N., Lambin, J., Vaze, P., and Lafon, T. (2009) The SWOT (Surface Water and Ocean Topography) Mission: Spaceborne Radar Interferometry for Oceanographic and Hydrological Applications. White Paper Submitted to OCEANOBS'09 Conference.

[10] Biancamaria, S., Andreadis, K.M., Durand, M., Clark, E.A., Rodríguez, E., Mognard, N.M., Alsdorf, D.E., Lettenmaier, D.P. and Oudin, Y. (2010) Preliminary Characterization of SWOT Hydrology Error Budget and Global Capabilities. IEEE Journal of Selected Topics in Applied Earth Observations and Remote Sensing, 3, 6-19. https://doi.org/10.1109/JSTARS.2009.2034614

[11] Papa, F., Biancamaria, S., Lion, C. and Rossow, W.B. (2011) Uncertainties in Mean River Discharge Estimates Associated with Satellite Altimeter Temporal Sampling Intervals: A Case Study for the Annual Peak Flow in the Context of the Future SWOT Hydrology Mission. IEEE Geoscience and Remote Sensing Letters, 9, 569-573. https://doi.org/10.1109/LGRS.2011.2174958

[12] Pedinotti, V., Boone, A., Decharme, B., Cretaux, J.F., Mognard, N., Panthou, G., Papa, F. and Tanimoun, B.A. (2012) Evaluation of the ISBA-TRIP Continental Hydrologic System over the Niger Basin Using in Situ and Satellite Derived Datasets. Hydrology and Earth System Sciences, 16, 1745-1773. https://doi.org/10.5194/hess-16-1745-2012

[13] Biancamaria, S., Durand, M., Andreadis, K.M., Bates, P.D., Boone, A., Mognard, 
N.M., Rodríguez, E., Alsdorf, D.E., Lettenmaier, D.P. and Clar, E.A. (2011) Assimilation of Virtual Wide Swath Altimetry to Improve Arctic River Modeling. Remote Sensing of Environment, 115, 373-381. https://doi.org/10.1016/j.rse.2010.09.008

[14] Durand, M., Fu, L.L., Lettenmaier, D.P., Alsdorf, D., Rodriguez, E. and Esteban-Fernandez, D. (2010) The Surface Water and Ocean Topography Mission: Observing Terrestrial Surface Water and Oceanic Submesoscale Eddies. Proceedings of the IEEE, 98, 766-779. https://doi.org/10.1109/JPROC.2010.2043031

[15] Chevalier, L., Laignel, B., Massei, N., Munier, S., Becker, M., Turki, I., Coynel, A. and Cazenave, A. (2013) Hydrological Variability of Major French Rivers over the Past Decades, Assessed from Gauging Stations and GRACE Observations. Hydrological Science Journal, 59, 1844-1855.

[16] Cleveland, W.S. (1979) Robust Locally Weighted Regression and Smoothing Scatterplots. Journal of the American Statistical Association, 74, 829-836. https://doi.org/10.1080/01621459.1979.10481038

[17] Cleveland, W.S. and Devlin, S.J. (1988) Locally Weighted Regression: An Approach to Regression Analysis by Local Fitting. Journal of the American Statistical Association, 83, 596-610. https://doi.org/10.1080/01621459.1988.10478639

[18] Torrence, C. and Compo, G.P. (1998) A Practical Guide to Wavelet Analysis. Bulletin of the American Meteorological Society, 79, 61-78. https://doi.org/10.1175/1520-0477(1998)079<0061:APGTWA >2.0.CO;2

[19] Labat, D. (2005) Recent Advances in Wavelet Analyses: Part 1. A Review of Concepts. Journal of Hydrology, 314, 275-288. https://doi.org/10.1016/j.jhydrol.2005.04.003

[20] Schneider, K. and Farge, M. (2006) Wavelets: Theory. In: Encyclopedia of Mathematical Physics, Elsevier, Amsterdam. https://doi.org/10.1016/B0-12-512666-2/00153-X

[21] Laignel, B., Massei, N., Rosse, A., Mesquita, J. and Slimani, S. (2010) Water Ressources Variability in the Context of Climatic Fluctuations on Both Sides of the Atlantic Ocean. International Association of Hydrological Sciences Publication, 340, 612-619.

[22] McCabe, G.J. and Wolock, D.M. (2002) A Step Increase in Streamflow in the Conterminous United States. Geophysical Research Letters, 29, 2185. https://doi.org/10.1029/2002GL015999

[23] Coulibaly, P. (2003) Impact of Meteorological Predictions on Real-Time Spring Flow Forecasting. Hydrological Processes, 17, 3791-3801.

https://doi.org/10.1002/hyp.5168

[24] Coulibaly, P. and Burn, D. (2004) Wavelet Analysis of Variability in Annual Canadian Streamflows. Water Resources Research, 40, 1-14. https://doi.org/10.1029/2003WR002667 